\title{
Reliability Assessment for PSC Box-Girder Bridges Based on SHM Strain Measurements
}

\author{
Chuang Chen, ${ }^{1}$ Zonglin Wang, ${ }^{2}$ Yinhui Wang, ${ }^{1}$ Tao Wang, ${ }^{1}$ and Zheng Luo' \\ ${ }^{1}$ School of Civil Engineering and Architecture, Ningbo Institute of Technology, Zhejiang University, Ningbo 315100, China \\ ${ }^{2}$ School of Transportation Science and Engineering, Harbin Institute of Technology, Harbin 150090, China
}

Correspondence should be addressed to Chuang Chen; chuang0925@hotmail.com

Received 2 January 2017; Revised 19 April 2017; Accepted 21 May 2017; Published 10 July 2017

Academic Editor: Emad Elbeltagi

Copyright (C) 2017 Chuang Chen et al. This is an open access article distributed under the Creative Commons Attribution License, which permits unrestricted use, distribution, and reproduction in any medium, provided the original work is properly cited.

A reliability assessment method for prestressed concrete (PSC) continuous box-girder bridges based on structural health monitoring (SHM) strain measurements was proposed. First, due to the fact that measured strain was compositive and the variation periods of its components were different, a series of limit state equations under normal use limit state were given. Then, a linear fitting method was used to determine the relationship between the ambient temperature and the measured strain, which was aimed at extracting the vehicle load effect and the temperature load effect from the measured strain. Finally, according to the equivalent normalization method, the load effects unsatisfying the normal distribution by probability density function fitting were transformed, and the daily failure probabilities of monitored positions were calculated for evaluating the safety state of the girder. The results show that (1) the top plate of the box girder is more sensitive than the bottom plate to the high temperature, (2) the daily and seasonal strain variations induced by uniform temperature reveal an inconsistent tendency to the seasonal variation for mid-span cross sections, and (3) the generalized extreme value distribution is recommended for temperature gradient stress and vehicle induced stress fitting for box-girder bridges.

\section{Introduction}

Typically, the structural health monitoring (SHM) technology is commonly considered as an efficient and effective tool acquiring the in-service behavior for structures during their life cycles [1]. Strain measurement, as the most common and important part of the SHM system, is usually used to monitor changes of critical points and sections of bridges [25]. Many researchers have tried to utilize the short-term and long-term monitoring strain responses to evaluate the state of bridges [6-8]. Moreover, the strain is used as an important detective parameter to identify damage and cracks in time series [9]. Strain responses are responsible for solving the fatigue assessment problem for the steel bridge [10].

However, for concrete structures, the strain is a complicated comprehensive variable determined not only by deformation but also by the ambient excitation variation (temperature, wind) and the property variation of the materials (concrete shrinkage and creep) [8]. The prestressed force plays a very important role in strain measurement during the long-term monitoring. All these factors make strain measurement, as an evaluation parameter, very difficult directly reflecting structure performance. Moreover, concrete bridges are usually subjected to the thermal effect which is normally caused by the temperature difference between the bridges and ambient environment, where solar radiation primarily leads to daily and seasonal temperature variation [11]. The nonlinear temperature distribution will lead to tensile stress along the depth of the sections and also lead to strain difference between the areas outside and inside the box girder, which are considered to be responsible for thermal cracks and damage [12].

The reliability methodology incorporation with SHM measurements to identify the damage and assess the condition of bridges was proposed in recent years [13]. It has mainly solved the randomness problem which greatly affects precisely evaluating the performance of bridges by using probability statistic methodology. Frangopol et al. [7] and Liu et al. $[14,15]$ have realized the reliability assessment of components on real bridges based on the long-term monitored data 
of SHM systems. Additionally, Li et al. [16] and Xia et al. [17] have applied the reliability analysis method for the condition assessment of Tsing Ma Bridge. Liu et al. [18] combined finite element analysis and radial basis function neural network with Monte-Carlo importance sampling method establishing a hybrid algorithm for reliability assessment of long-span prestressed concrete cable-stayed bridges. Wang et al. [19] compared three extreme value selection methods of vehicle load, and their results show that the different method for choosing the vehicle response may affect the reliability of bridges. Liu at al. have developed a holistic reliability assessment framework considering the cable breakage incident for the long-span cable bridge. However, applications of the reliability method on concrete box-girder bridges using the measurements from SHM systems are limited to date.

The bridge is commonly subjected to plenty of loads with high degree of randomness. Therefore, how to use this random load responses from the SHM system to assess safety condition is a main issue. The reliability method utilizes probabilistic methodology solving the load effects randomness and provides a new solution for assessing the safety condition of concrete box-girder bridges. In this study, a reliability assessment method for PSC continuous box-girder bridges based on SHM strain measurements was first proposed. Then, a reliability calculation case based on strain measurements of a long-term SHM system of a prestress concrete (PSC) continuous box-girder bridge was presented. According to the stress characteristics and load reference period in the operation stage of concrete box-girder bridge, limit state equations under normal using limit state were given due to the measured compositive strain and the different variation periods of its components. The probability density function fitting of the load effect dissatisfying the normal distribution was transformed according to equivalent normalization method (JC method). The daily failure probabilities of monitored positions were calculated for assessment of this bridge. This study provides a methodology of reliability assessment for concrete box-girder bridges which has simultaneously taken into account the vehicle load effect and the temperature load effect.

\section{Reliability Evaluation Method}

2.1. Component Analysis of Measured Strain Responses. For concrete box-girder bridges, in order to attain long-term data credibly in order to reduce the influence of the external environment on data and to improve the service life of sensors, the monitoring system including used sensors is usually arranged on interior of the box girder. Therefore, for longterm measured responses, for example, strain monitoring data can be expressed as

$$
\lambda_{M}=\lambda_{T}+\lambda_{\mathrm{EF}}+\lambda_{\mathrm{IF}}+\lambda_{\mathrm{C}}+\lambda_{N}+\lambda_{\mathrm{O}}
$$

where $\lambda_{M}$ is measured strain; $\lambda_{T}$ is temperature produced strain; $\lambda_{\mathrm{EF}}$ are external forces producing strain, for concrete continuous box-girder bridge, which mainly refer to vehicle load producing strain; $\lambda_{\text {IF }}$ are internal forces including dead load and prestressed load producing strain; $\lambda_{C}$ is creep and shrinkage strain; $\lambda_{N}$ is measured noise; and $\lambda_{O}$ are accidental actions producing strain.

From formula (1), long-term monitoring strain response is comprehensive while its components have different time scale. Researches show that (1) temperature of bridge structure is usually affected by external environment factors such as geographical conditions and intensity of solar radiation. The surface temperature of the box-girder changes at the same time scale as atmospheric temperature. Daily temperature difference, annual temperature difference, and abrupt temperature drop are the biggest factors affecting bridge structures. Obviously, (1) the unit of daily temperature difference and annual temperature difference are one day and one year for time scales, respectively. The abrupt temperature drop, on time scale, has its randomness, which completes over a few days; (2) when a vehicle passes through a bridge, the duration is very short lasting several minutes, so the minute is considered as the time scale; (3) Concrete shrinkage and creep last the whole lifetime of the structure for years, and the variation, in general, uses the month as time scale already satisfying accuracy requirement; (4) the variation of the dead load and prestress will occur for a long time during bridge operating process, so considering the month as time scale also has enough accuracy; and (5) noise influence is a random and uncertainty process which can be considered as a random variable and the time scale distribution is in a wide range. As a result, in daily time scale, for the bridge structure condition assessment, one only needs to consider the influences of temperature difference, vehicle load, and noise.

2.2. Normal Use Limit State Equation. For the bridge with infrequent traffic, the role of environmental factors may be greater than the effect of the vehicle load. Therefore, condition assessing is focused on the performance of the normal use during the whole lifetime of bridges. During normal use process of concrete continuous box-girder bridges, on daily time scale, daily temperature difference and the vehicle load play main roles in bridge condition assessment. Specifically, daily uniform temperature variation mainly produces expansion deformation along the beam direction and vertical temperature gradient mainly produces temperature subinternal force across cross sections. The overall longitudinal deformation is not useful for the box girder. As we all know, vertical temperature gradient stress will take responsibility for the temperature cracks on the concrete box girder. Therefore, during the benchmark period of the concrete box-girder bridge structure, the concrete tensile strength standard value can be considered as the resistance in the normal use limit state equation. The load effects are dead load, vehicle load, and temperature gradient stress, respectively. These three kinds of load effects are independent of each other, so as to establish the in-service concrete continuous box-girder bridges cross section limit state equation as

$$
\begin{aligned}
G= & Z_{S}(x, t)+\varphi_{0}(x, t) Z_{D}(x, t) \\
& -\left(1+\varepsilon_{1}\right) \varphi_{1}(x, t) Z_{V}(x, t) \\
& -\left(1+\varepsilon_{2}\right) \varphi_{2}(x, t) Z_{T}(x, t),
\end{aligned}
$$


where $Z_{S}(x, t)$ is the concrete tensile strength standard value; $Z_{D}(x, t)$ is the dead load effect after the bridge completed; $Z_{V}(x, t)$ is the measured vehicle load effect; $Z_{T}(x, t)$ is the measured temperature gradient load effect; $\varphi_{0}(x, t)$ is the time variation function of the dead load effect; $\varphi_{1}(x, t)$ is the time variation function of the vehicle load effect; and $\varphi_{2}(x, t)$ is the time variation function of the temperature gradient effect. The time variation functions can be used to predict the response of the future. $\varepsilon_{1}$ and $\varepsilon_{2}$ are monitoring errors, respectively, assuming that they satisfy the normal distribution $N(0, \sigma)$. The reliability index of the limit state equation is shown as follows:

$$
\beta=\frac{\alpha_{S}+\alpha_{D}-\alpha_{V}-\alpha_{T}}{\sqrt{\delta_{S}^{2}+\delta_{D}^{2}+\delta_{V}^{2}+\delta_{T}^{2}}}
$$

where $\alpha_{S}$ is the mean of the concrete tensile strength standard values; $\alpha_{D}$ is the mean stress caused by dead load; $\alpha_{V}$ is the mean stress caused by vehicle load; $\alpha_{T}$ is the mean stress caused by temperature gradient load; $\delta_{S}$ is the standard deviation of concrete tensile strength standard values; $\delta_{D}$ is the standard deviation stress caused by dead load; $\delta_{V}$ is the standard deviation stress caused by vehicle load; and $\delta_{T}$ is the standard deviation stress caused by temperature gradient load.

Under the effect of the vehicle load, according to the flat section assumption, the top plate of the box girder along the longitudinal presents compression stress and the bottom plate presents tensile stress. Therefore, when calculating the top plate reliability index, according to the most unfavorable principle, the vehicle load effect is not counted. Under the effect of the temperature gradient load, tension and compression both act on the top plate and the bottom plate. Therefore, the limit state equation (6) can be represented according to the most unfavorable load combination only taking into account the temperature gradient load effect as

$$
\begin{aligned}
G_{T}= & Z_{S}(x, t)+\varphi_{0}(x, t) Z_{D}(x, t) \\
& -\left(1+\varepsilon_{2}\right) \varphi_{2}(x, t) Z_{T}(x, t) .
\end{aligned}
$$

Correspondingly, the reliability index can be rewritten as

$$
\beta_{T}=\frac{\alpha_{S}+\alpha_{D}-\alpha_{T}}{\sqrt{\delta_{S}^{2}+\delta_{D}^{2}+\delta_{T}^{2}}} .
$$

When calculating the reliability index of the bottom plate, only vehicle load effect is taken into account because of the temperature gradient load producing compression stress, so the limit state equation can be represented as

$$
\begin{aligned}
G_{V}= & Z_{S}(x, t)+\varphi_{0}(x, t) Z_{D}(x, t) \\
& -\left(1+\varepsilon_{1}\right) \varphi_{1}(x, t) Z_{V}(x, t) .
\end{aligned}
$$

Then, the reliability index can be described as

$$
\beta_{V}=\frac{\alpha_{S}+\alpha_{D}-\alpha_{V}}{\sqrt{\delta_{S}^{2}+\delta_{D}^{2}+\delta_{V}^{2}}} .
$$

According to the previous analysis, a method which is used to evaluate the condition of concrete box-girder bridges based on strain measurements is proposed, where the evaluation process is illustrated in Figure 1.

\section{A Case for Reliability Calculation}

3.1. Fu Sui Bridge and Its SHM System Description. The prestress concrete continuous box-girder bridge is located at Heilongjiang province $\left(\mathrm{N} 47^{\circ} 14^{\prime} 40^{\prime \prime}, \mathrm{E} 131^{\circ} 58^{\prime} 11^{\prime \prime}\right)$ of mainland of China (shown in Figure 2). The bridge is $1170 \mathrm{~m}$ long and is composed of six $150 \mathrm{~m}$ long main spans and two $85 \mathrm{~m}$ long side spans. The vertical heights of supporting sections and mid-span sections are $9 \mathrm{~m}$ and $3.5 \mathrm{~m}$, respectively. Castin-place cantilever posttensioned construction method was adopted for the single-cell box girder. Each cantilever arm was $74 \mathrm{~m}$ in length, which was divided into 19 segments (\#0 to \#18). The entire construction process lasted for three years from 2008 to 2011.

In order to detect the damage and evaluate the longterm static and dynamic performances under the influences of traffic and ambient environment, a long-term SHM system was designed and implemented on this bridge. The system was composed of a hydrostatic leveling subsystem (HLS), a fiber Bragg grating (FBG) sensor subsystem, a data acquisition and transmission subsystem, a master control center, a remote control center, data analysis and processing software, and a power supply system (Figure 3). Detailed information of SHM system can be found elsewhere [20, 21].

Sensor positions of the SHM system are shown in Figure 4 . There are two types of the sensor for the monitoring system. Fiber Bragg grating sensors were applied to monitor temperature, strain, and vibration. Inductance type sensor was applied for displacement. Totally, 24 self-adaptive strain sensors which were usually installed on inner surface of the top plate and the bottom plate were distributed on six sections of the box girder. A temperature sensor was applied to every strain section. In section T (as shown in Figure 4), six temperature sensors were applied to monitor the inside and outside temperature variation of the girder. The field sensor distribution of section B is presented in Figure 5.

3.2. Monitoring Strain and Temperature. From May 2012 to April 2013, strain measurements were presented to investigate the relationship with the temperature. For concrete boxgirder bridges, temperature distribution on bridge components can be described as the uniform temperature and the temperature gradient.

The uniform temperature variation can only cause the expansion and compression along the girder in length. However, the temperature gradient variation normally induces the girder bending deformations which is considered as the main reason of local cracking [22]. For a continuous bridge, only one bearing support fixed can eventually restrict the girder against the longitudinal and lateral movements. Under the uniform temperature load, the girder can freely expand and compress in longitudinal direction. However, uniform temperature-induced distortion may be restricted due to 


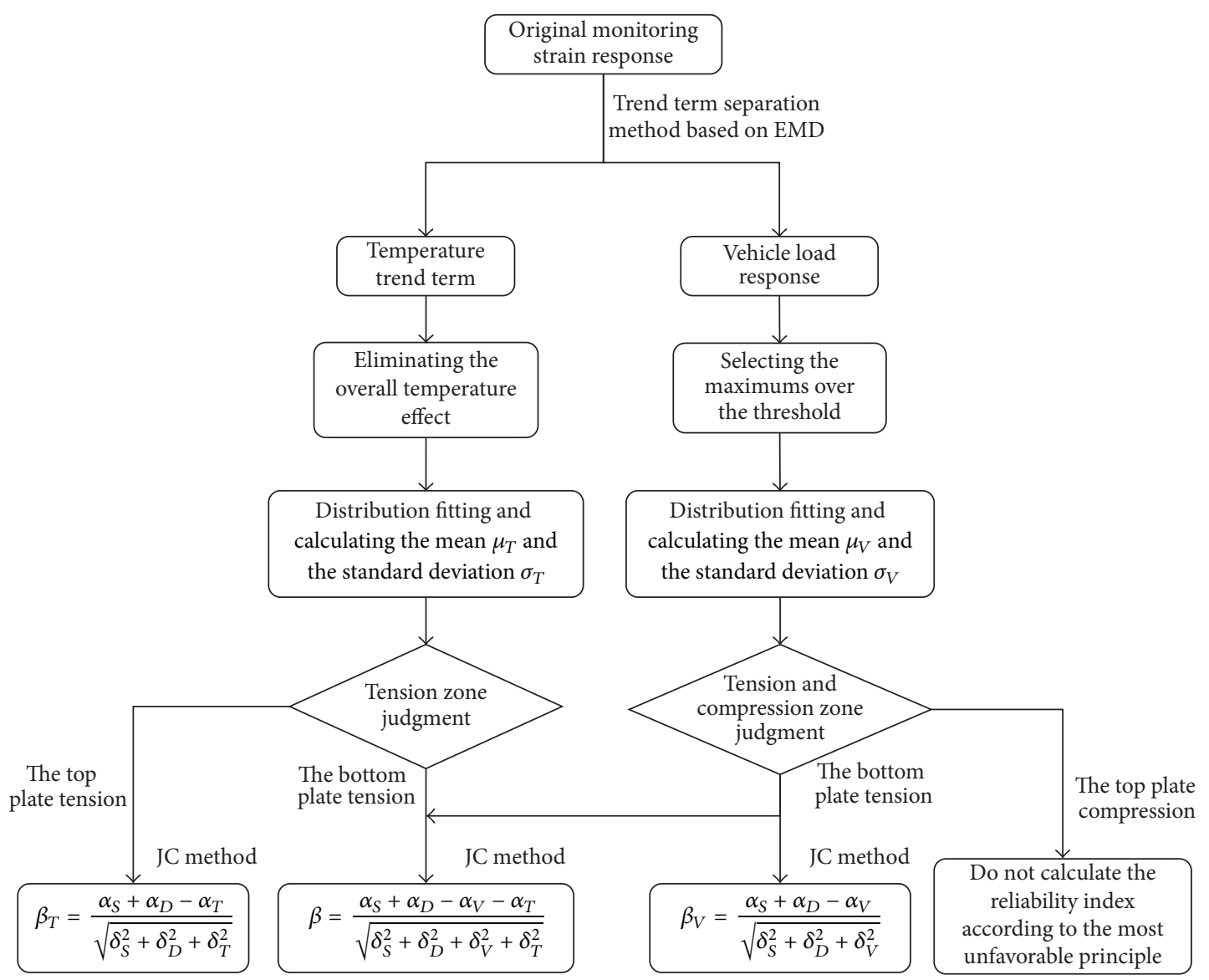

Figure 1: Flow chart of reliability index calculation.

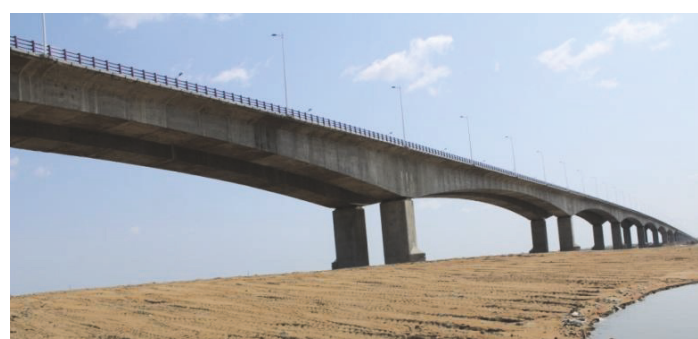

Figure 2: The view of the bridge.

friction force existence in other supports. In the early stage of the uniform temperature load, it can be imaged that the girder expansion movement may not happen. But it may exceed the bearing sliding friction force along with the expanding force accumulating. Finally, the girder longitudinal movement happens. The entire processing can be described as an energy accumulation and releasing cycle.

3.2.1. Uniform Temperature-Induced Strain. Generally, longitudinal strain measurement in accordance with the longitudinal deformation of the girder presents the approximately linear relation with the uniform temperature variation. Strain measurements and one-day temperature variation inside and outside the box-girder are presented in Figure 5.

Figure 6 shows that the outside temperature magnitude is usually much bigger than the inside temperature magnitude. The strain variation represents positive correlation with the outside temperature of box girder in spite of whether in summer or winter. In summer, the strain also increases to the maximum value when the temperature reaches the highest value (at $16 \mathrm{pm})$. Similarly, the peak presents at $13 \mathrm{pm}$ in winter, and the strain may lag for a while to arrive at its peak. Overall, the strain changes the same as the outside temperature variation in daily measurement. Therefore, a linear regression analysis was carried out using the outside temperature measurements and the strain measurements of section D. The regression results are shown in Figures 7 and 8.

Figures 7 and 8 show the daily strain linear regression with the outside temperature variation. One-day strain measurements of section D were selected from summer in 2012 and winter in 2013, respectively. From these figures, it can be seen that the linear regression slopes, even when all are from the same section, were different from each other regardless of the season difference. It is one evidence of temperature gradient which is a common property existing in box-girder bridges. 


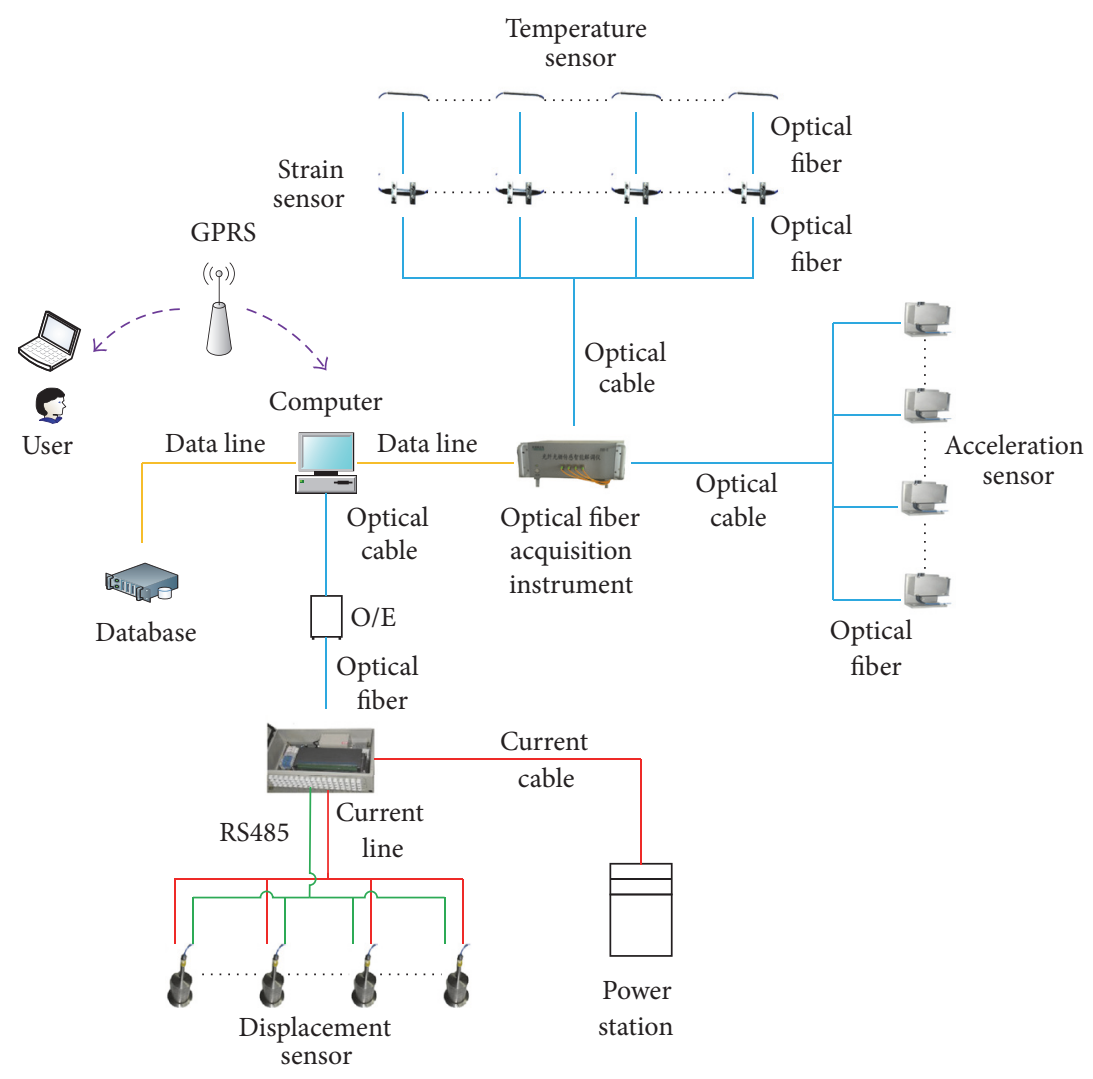

FIGURE 3: SHM system of Fu Sui bridge.

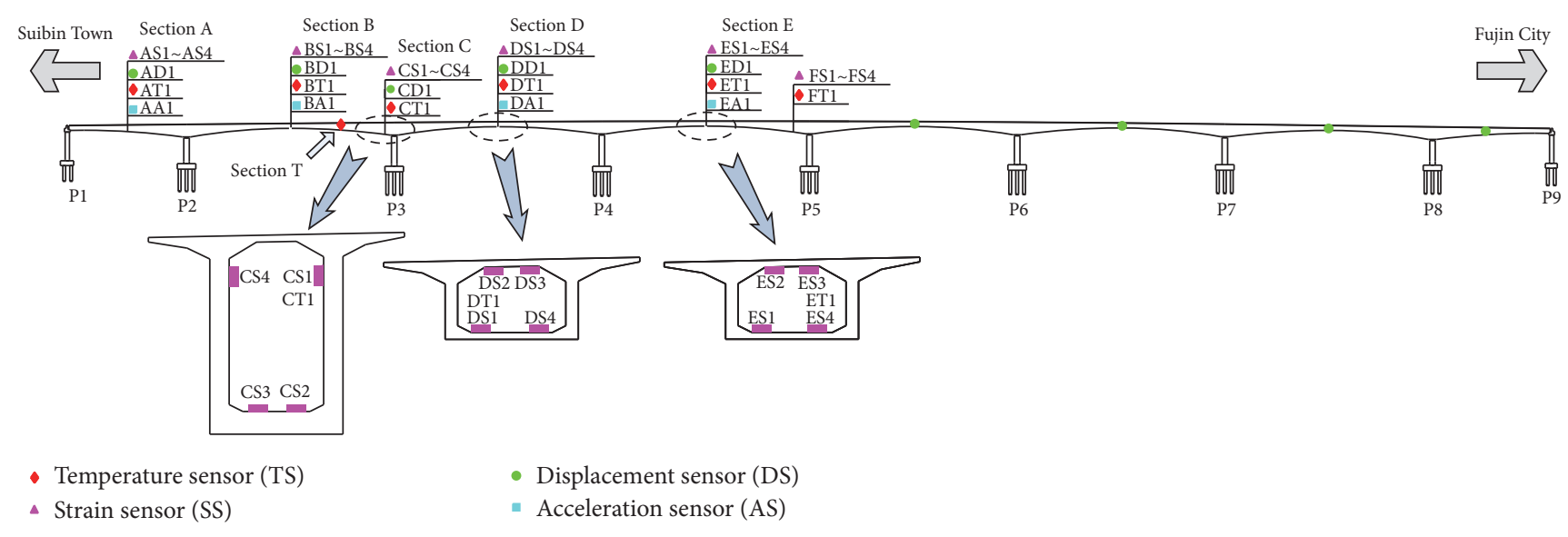

FIGURE 4: Elevation and positions of sensors.

Linear regression coefficients between the outside temperature and strain measurements and their $R^{2}$ values are presented in Table 1. It can be observed that $R^{2}$ values are all effective except for two values (the DS1 and DS4 in summer), which means that linear regression method is suitable for describing the relationship between the outside temperature and strain measurements. The slope magnitude $\left.a(\mu \varepsilon)^{\circ} \mathrm{C}\right)$ can reflect the strain sensitivity to the outside temperature variation. In summer, the slopes of the top plate are much bigger than the ones of the bottom plate, which means that the top plate is more sensitive to the uniform temperature variation. This suggests that high temperature is more effective on the top plate. However, in winter, the slopes of the bottom plate grow much bigger, which suggests that low temperature can produce strain more easily on the bottom plate.

Figure 9 shows one-day mean-temperature variation inside and outside the box-girder from May 2012 to April 2013. 
TABLE 1: Linear regression coefficients between temperature and strain measurements and their $R^{2}$ values.

\begin{tabular}{lccr}
\hline Sensor & Time & $a$ & $R^{2}$ \\
\hline DS1 (on bottom plate) & & 1.452 & 0.6067 \\
DS2 (on top plate) & Summer (2012.6.21) & 2.19 & 0.8750 \\
DS3 (on top plate) & & 3.038 & 0.9121 \\
DS4 (on bottom plate) & & 1.049 & 0.5573 \\
DS1 (on bottom plate) & Winter (2013.1.21) & 2.04 & 0.9078 \\
DS2 (on top plate) & & 1.897 & 0.9304 \\
DS3 (on top plate) & & 2.242 & 0.8277 \\
DS4 (on bottom plate) & & 1.714 & 0.7966 \\
\hline
\end{tabular}

${ }^{*} y=a x$, where $y$ means strain and $x$ means temperature variation; $R^{2}$ means coefficient of determination.

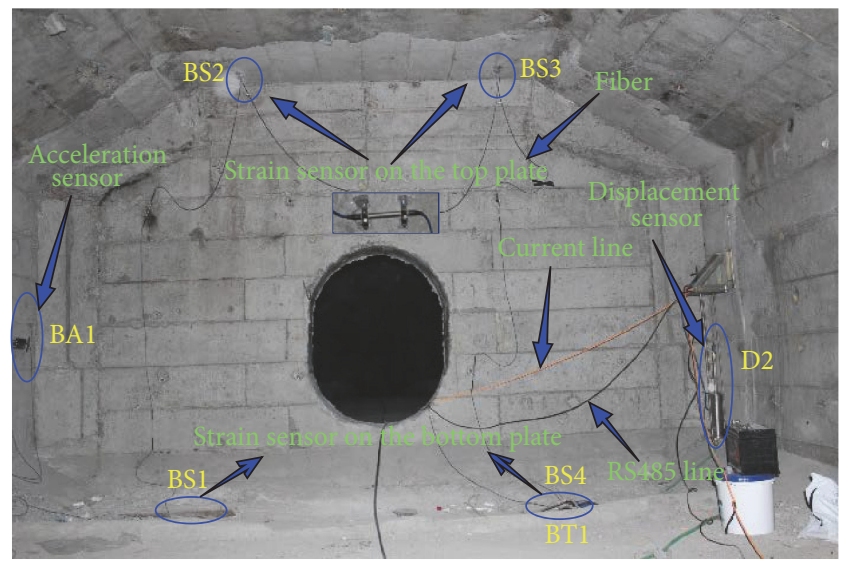

Figure 5: Sensors distribution of section B.

Figure 9 shows the temperature variation outside and inside the box girder. Generally, the temperature measurements are consistent with the seasonal climate feature at the bridge site where the daily temperature difference is very big both in summer and in winter. Overall, the ambient temperature can drop from $30^{\circ} \mathrm{C}$ (in summer) down to $-20^{\circ} \mathrm{C}$ (in winter). The temperature variation not only influences the property of concrete, but also redistributes the internal forces and changes the boundary conditions of bridges.

Figure 10 shows the strain variation from May in 2012 to May in 2013. The curve decreasing means the tensile strain and the curve increasing means the compressive strain. It is interesting that the seasonal strain variation presents a negative correlation with the uniform temperature in time series, which is contrary to the daily strain variation trend with the temperature. The main reason is that the seasonal temperature can generate the longitude expansion and compression along the deck especially for this kind of continuous concrete bridges with the extremely long deck. Meanwhile, the bridge has no longitude restrictions, which makes the longitude expansion and compression occur freely. Therefore, in winter, the deformation of the mid-section of the continuous bridge goes down, which can cause the tensile strain on the mid-section; in summer, the deformation of the mid-section goes up, so the strain of the mid-section is compressive and keeps on decreasing. From Figure 9, four strain sensors arranged on section $\mathrm{D}$ all present consistency with the above theory. Therefore, the seasonal temperature variation is more effective on the strain of concrete bridges in cold region.

3.2.2. Temperature Gradient Induced Strain Difference. In particular, concrete box-girder bridges normally produce temperature gradient stress along the vertical cross sections due to solar radiation and abrupt temperature dropping. This property currently is considered as one of the main reasons which induce the cracking and local damage for concrete boxgirder bridges. One-day strain measurements of section $\mathrm{D}$ on June 21 are shown in Figure 11.

The sampling frequency of the monitoring system is 60 times per hour. $\Delta S_{1}$ and $\Delta S_{2}$ are the strain difference between the top plate and the bottom plate of the mid-span cross section. The strain of the top plate happens earlier than the bottom plate reaching the peak at around $16 \mathrm{pm}$; then the strain of bottom plate reaches the peak at about $19 \mathrm{pm}$. It demonstrates that the solar energy needs a couple of hours transferring along the vertical cross section from the top plate to the bottom plate. When the strain rises up before reaching the peak, the strain differences $\Delta S_{1}$ and $\Delta S_{2}$ between top and bottom plates are positive, which means the top plate is tensile relative to the bottom plate, although its amplitude keeps on decreasing; after the strain reaches the peak, it drops quickly without the solar energy while the strain of the bottom plate goes down relatively slowly; then the $\Delta S_{1}$ and $\Delta S_{2}$ difference directions turn to be negative, which means the bottom plate is tensile. It can been seen that the strain of the top plate declines faster than the bottom plate. Therefore, the solar energy transfer lag is responsible for generating vertical temperature gradient stress in cross sections. With daily temperature gradient effect recycle, the cross sections potentially can have cracks and be damaged.

3.3. Temperature-Induced Response Separation. Uniform temperature strain response is usually considered as a trend term in original measurements. A number of trend term separation methods have been developed, such as empirical mode decomposition (EMD) method, low pass filtering method, wavelet method, least square method, and average slope method. In this study, EMD method was adopted to separate the temperature trend term. A more 




- - - Outside box girder Inside box girder - DS2

(a) One-day measured strain and temperature on Jun 21, 2012

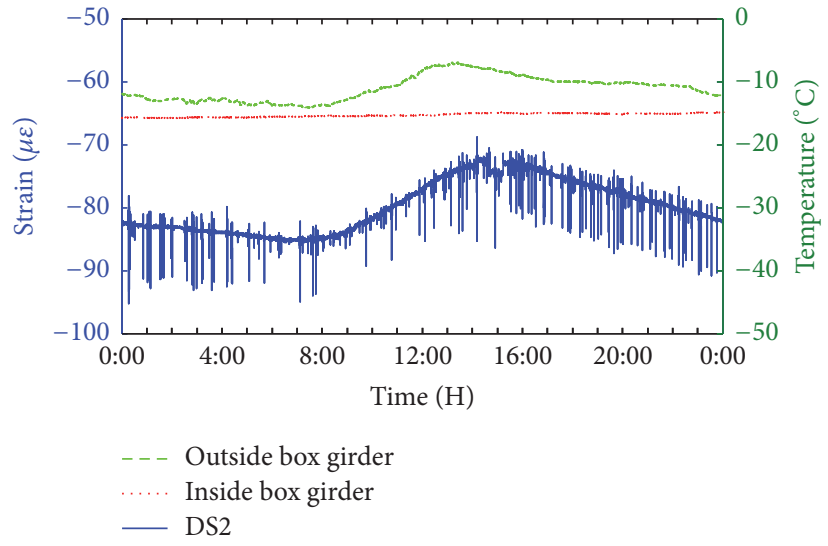

(b) One-day measured strain and temperature on Jan 21, 2013

Figure 6: One-day measured strain and temperature.

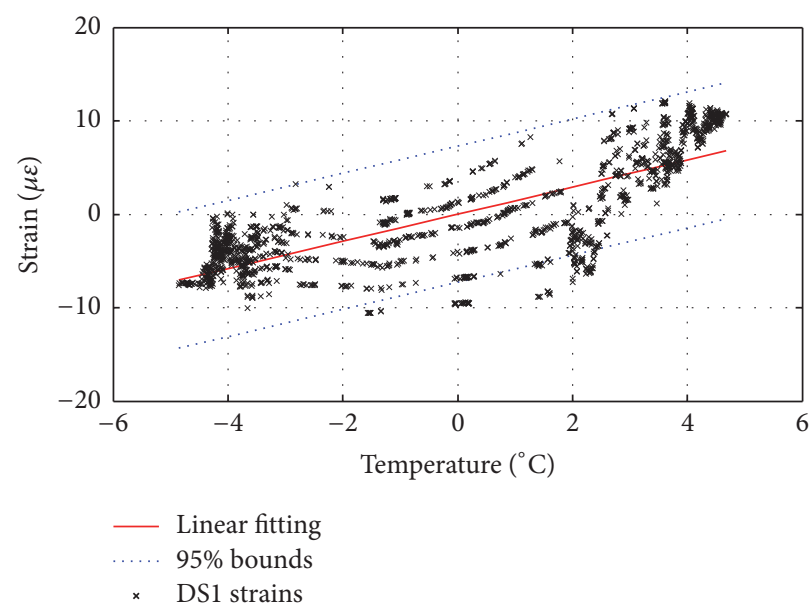

(a) Linear fitting of DS1

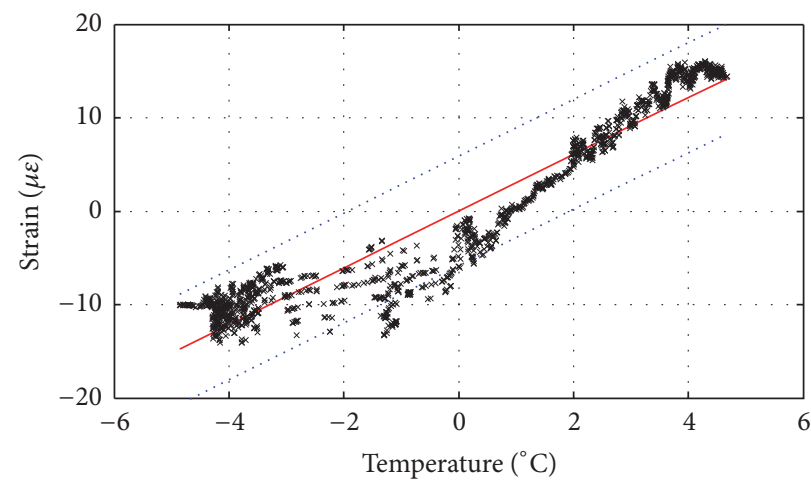

- Linear fitting

$95 \%$ bounds

* DS3 strains

(c) Linear fitting of DS3

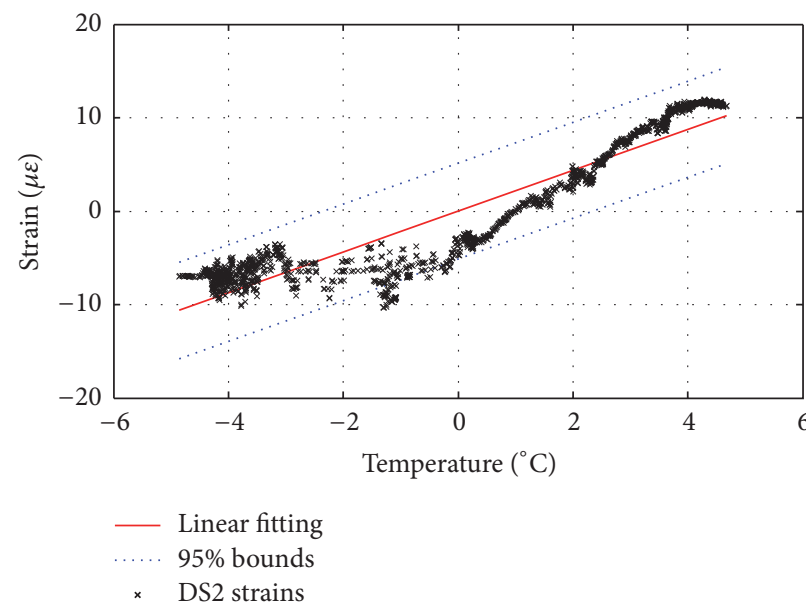

(b) Linear fitting of DS2

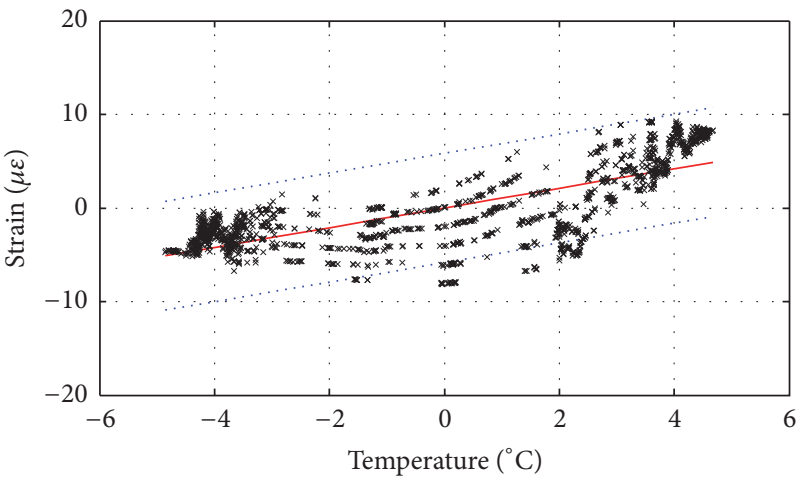

- Linear fitting $95 \%$ bounds

$\times \quad$ DS4 strains

(d) Linear fitting of DS4

FIgURE 7: One-day strain linear regression of four sensors on section D on 21 June, 2012. 


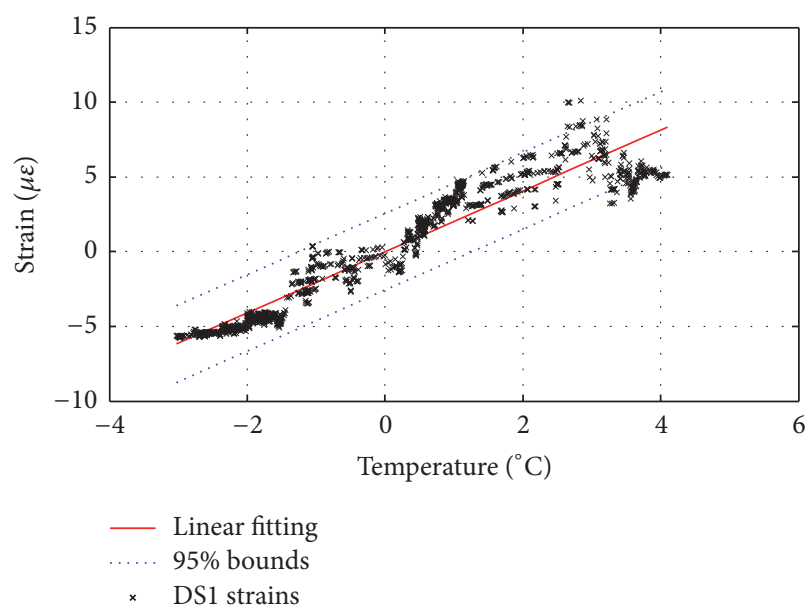

(a) Linear fitting of DS1

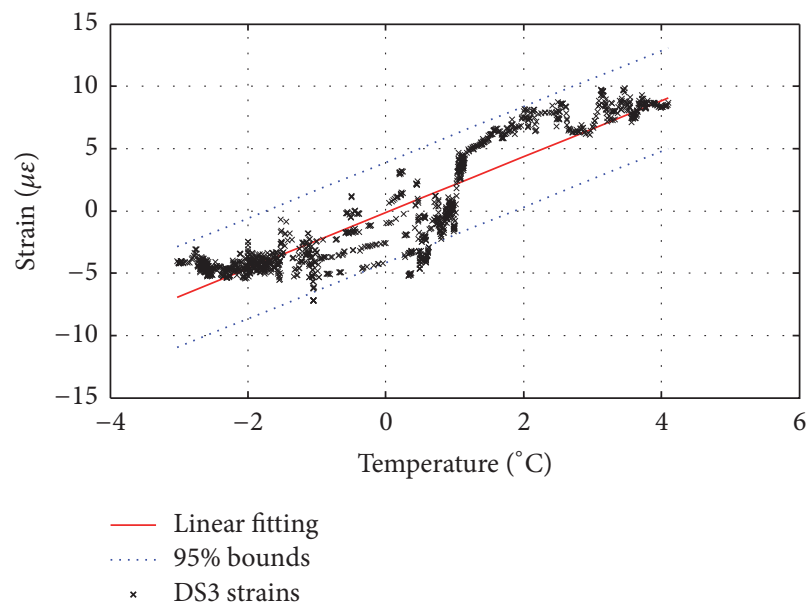

(c) Linear fitting of DS3

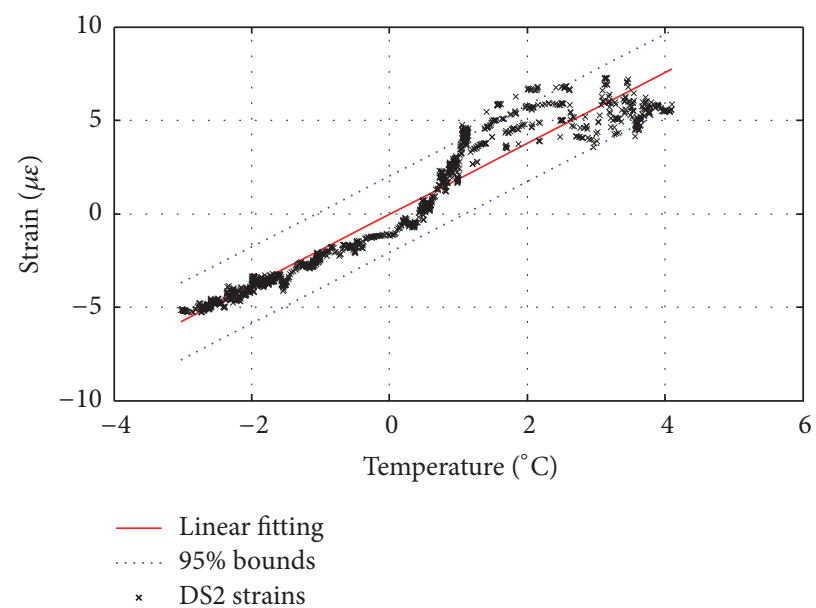

(b) Linear fitting of DS2



(d) Linear fitting of DS4

FIGURE 8: One-day strain linear regression of four sensors on section D on 21 January, 2013.

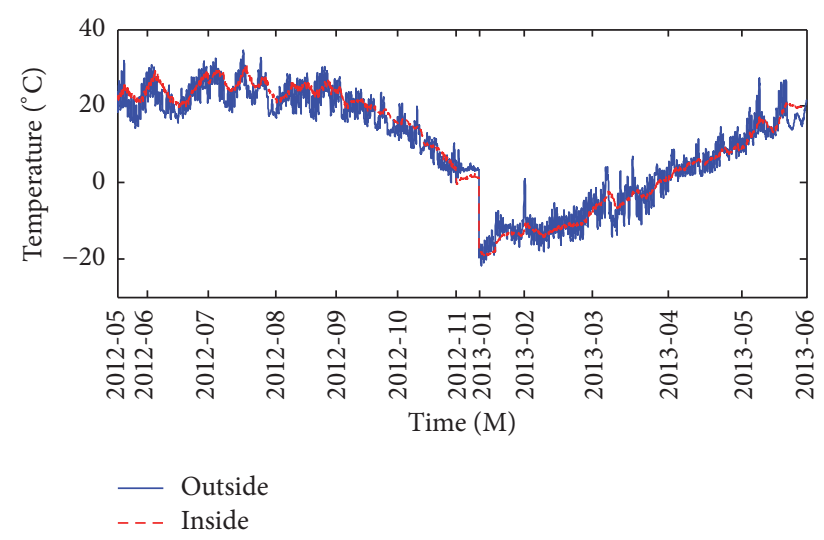

FIGURE 9: One-year temperature variation for Fu Sui Bridge.

efficient EMD method was developed rather than directly using EMD method to decompose the original signal. For a long-term monitoring dynamic signal, a large amount of data was directly decomposed into intrinsic mode functions

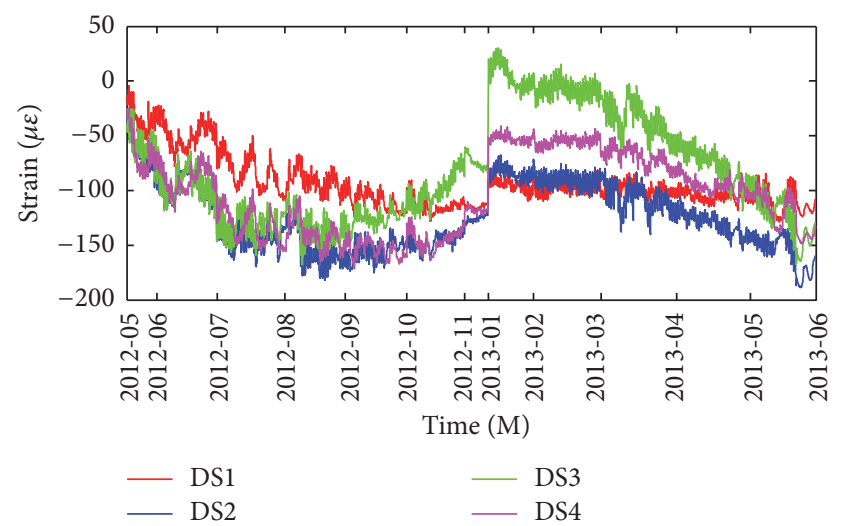

FIGURE 10: One-year strain variation of section D.

(IMFs) that the whole iterative calculation process will take up a lot of CPU, memory, and time. Therefore, a solution was to cut the whole signal into several subsections by one-day signal length. Each subsection was operated for 


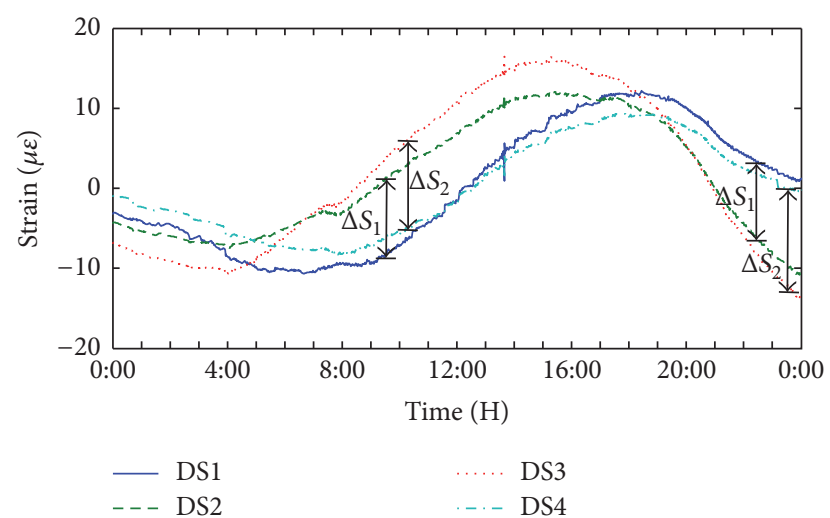

FIGURE 11: One-day monitoring strain responses of section D on June 21, 2012. ${ }^{*} \Delta S_{1}, \Delta S_{2}=$ the strain difference between the top plate and the bottom plate.

downsampling obtaining a new signal to be dealt with by the EMD method. After this process, a residual in accordance with the trend term was prepared for upsampling with the cubic spline interpolation method which was aimed at restoring the residual to original length. As a result, one-day trend term was obtained. Then, the overall trend term can merge sequentially all the subsection trend term signals together. This method can greatly and effectively reduce the calculation cost and time cost for trend term extraction of long-term monitoring data.

Original monitoring strain responses of DS3 and DS4 were shown in Figure 12 with the data selected from June 14 to June 23, 2012. Through the separation trend term method previously mentioned, the signals after deleting the trend term are shown in Figure 13, and trend terms are shown in Figure 14.

3.4. Probability Density Function Fitting. In order to calculate the reliability index, probability density distribution function of each load effect in the limit state equation needs to be attained firstly. Researches show that the concrete tensile strength standard value and the dead load both satisfy the normal distribution. According to the equivalent normalization method, one should estimate the distribution of the vehicle load effect and the temperature gradient load effect. If they do not satisfy the normal distribution, equivalent normalization process may be needed to make effects satisfy normal distribution.

During the whole monitoring process, it is assumed that the concrete material property satisfied Hooke's Law; namely, $\sigma=E \cdot \varepsilon$, where $\sigma$ and $\varepsilon$ were the stress and measured strain and $E$ was the modulus of elasticity which was adopted as $4.1 \times 10^{4} \mathrm{MPa}$ (the average value of the measured concrete modulus of elasticity on the 28th day). Thus, the measured strain can be transformed to stress instead.

\subsubsection{Probability Density Function Fitting of Temperature} Gradient Load Stress. A probability density function fitting was carried out with extracted temperature trend term strain. Firstly, a preprocessing procedure was operated on the trend term by resetting the daily relative zero starting points at the same moment when the temperature-induced strain, in top plate and in bottom plate, was varying almost consistently. In this case, 0 am was chosen to be the starting point of the daily trend term. The purpose of resetting the zero starting point was to eliminate the influence of the cumulative effect. Therefore, the one-day trend term was only affected by the intraday temperature variation. According to the assumption that the cross section had the same longitudinal deformation under the overall temperature load, the relative strain between the top plate and the bottom plate can eliminate this uniform temperature-induced strain and the difference values can be considered as the temperature gradient strain.

Probability density function (PDF) fitting results of the temperature gradient stress are depicted in Figure 15. Generalized extreme value (GEV) distribution is used to fit the histogram of the relative stress of DS4-DS3. The temperature gradient stress presents randomness and approximatively satisfies the GEV distribution.

\subsubsection{Probability Density Function Fitting of Vehicle Load} Stress. Currently, there are two basic methods to use the vehicle load stress values for calculation. The first method directly applies the monitoring vehicle load response for structure reliability assessment. Another method only uses extreme values of the vehicle load stress. For vehicle load stress extremum selection, there are also two options: (1) considering the daily maximum as the monitoring extremum; (2) taking all the monitoring extremums which are bigger than the threshold. In this case, a threshold was set and all the extremums bigger than the threshold were selected for the probability density distribution function fitting. Through the analysis of the measured vehicle load stress responses, it was found that the absolute values less than $0.06 \mathrm{MPa}$ were noise. In addition, $0.25 \mathrm{MPa}$ and $0.30 \mathrm{MPa}$ were decided as thresholds for DS3 and DS4, respectively.

Four kinds of the PDF distribution fitting were carried out for the vehicle load stress responses of DS3 and DS4 which were shown in Figure 16. The maximum likelihood method was used to compare the fitting results of these four distributions. From the calculation results, GEV distribution fitting was better than others. So in this case, the vehicle load stress response was considered as satisfying the GEV distribution.

3.5. Failure Probability Results and Discussion. The failure probability of the monitoring position was calculated as the flow (Figure 11). The distributions of temperature gradient load stress and vehicle load stress have been given according to the previous fitting. The vehicle load stress and the temperature gradient load stress of the monitoring positions are combined with the most unfavorable principle for the bridge. The different combination selects the suitable formula to calculate the reliability index which generally has a certain relationship with the failure probability. The combinations and their suitable formulas are shown in Table 2. In particular, JC method requires that the random parameters all satisfy 
TABLE 2: Calculation combination of reliability index.

\begin{tabular}{|c|c|c|c|c|c|}
\hline Combination & \multicolumn{2}{|c|}{ Vehicle load stress } & \multicolumn{2}{|c|}{ Temperature gradient load stress } & Reliability index calculation formula \\
\hline 1 & DS3 $<0$ & Top plate tension & DS4-DS3 $<0$ & Top plate tension & (5) \\
\hline 2 & DS $4>0$ & Bottom plate tension & DS4-DS3 $>0$ & Bottom plate tension & (3) \\
\hline 3 & DS $4>0$ & Bottom plate tension & DS4-DS3 $<0$ & Top plate tension & (5), (7) \\
\hline
\end{tabular}

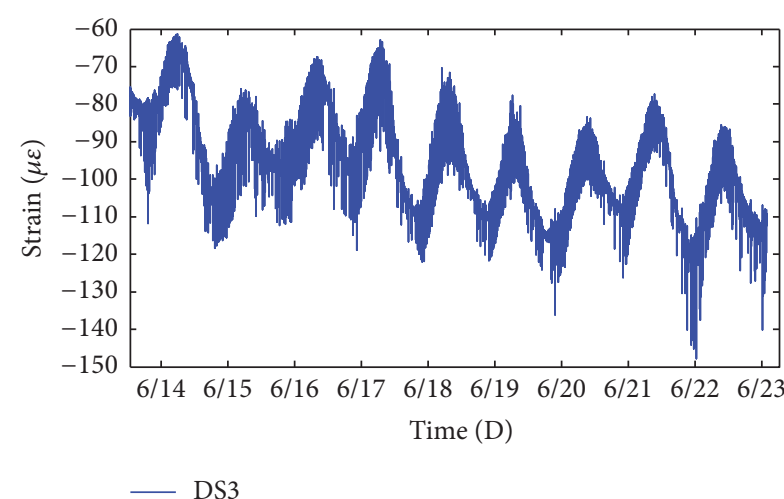

(a) Strain response of DS3

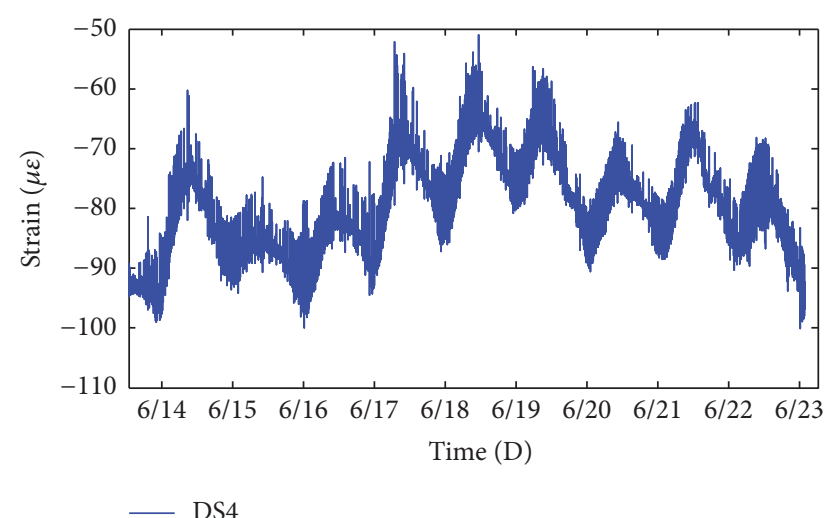

(b) Strain response of DS4

FIGURE 12: Strain time history signals of section D.

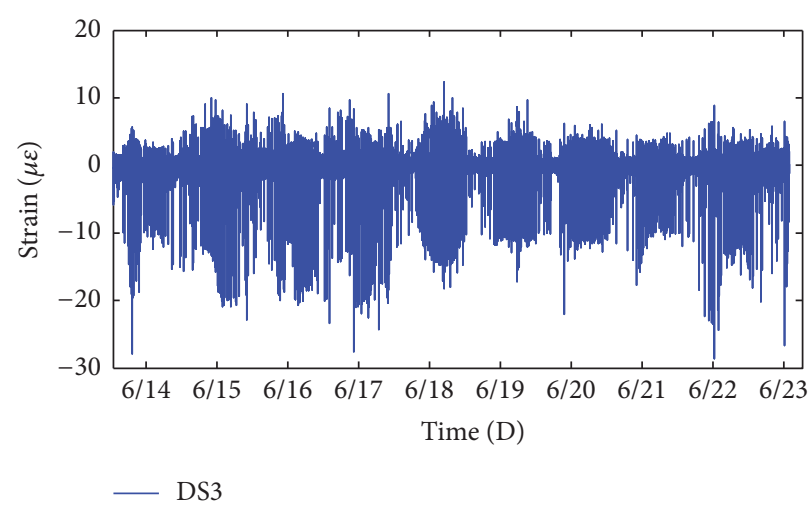

(a) DS3 signal after deleting the trend term

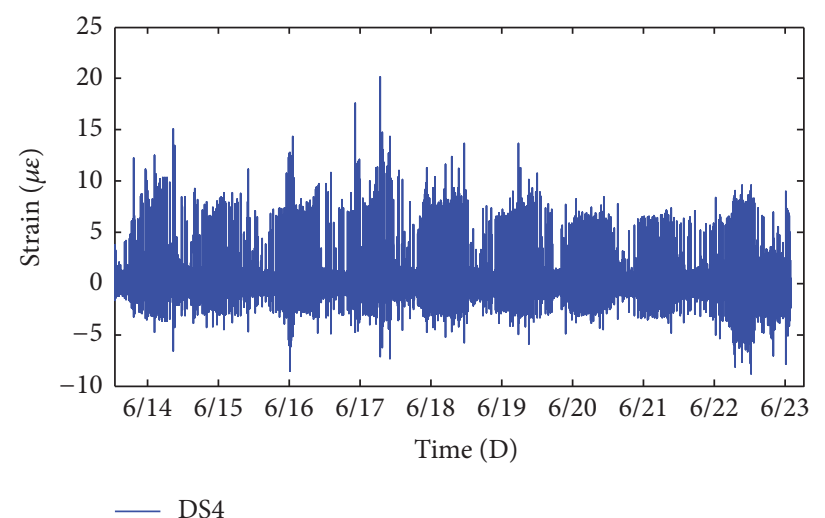

(b) DS4 signal after deleting the trend term

FIGURE 13: Strain signals after deleting the trend term.

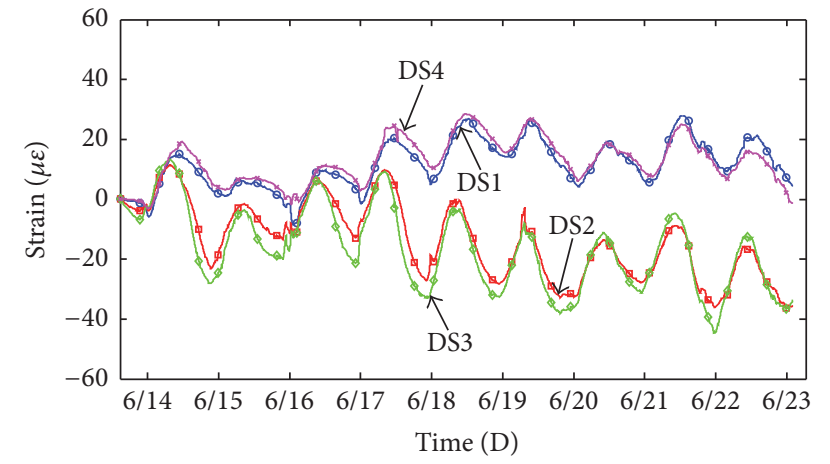

FIGURE 14: Trend terms of strain responses.

the normal distribution. That is the reason why the measurements with abnormal distributions, such as vehicle load stress and temperature gradient load stress, were conducted for the transformation through equivalent normalization.

In this case, the concrete tensile strength standard value was $2.65 \mathrm{MPa}$ with the variable coefficient of 0.15 . It is difficult to directly measure the dead load stress mean value in completed bridge state. Thus the finite element analysis calculated dead load stress mean value was used instead, and its variable coefficient was adopted for 0.0462 . The vehicle load stress and temperature gradient stress were used in the field measured data to calculate the real mean values and standard deviations. According to calculated reliability index flow shown in Figure 11, the failure probability of monitoring positions was calculated (Figure 17).

For the mid-span cross sections, such as section D and section $\mathrm{E}$, there is no value if the temperature gradient load stress presents as tensile on the bottom plate. Correspondingly, the failure probabilities of the bottom plates 


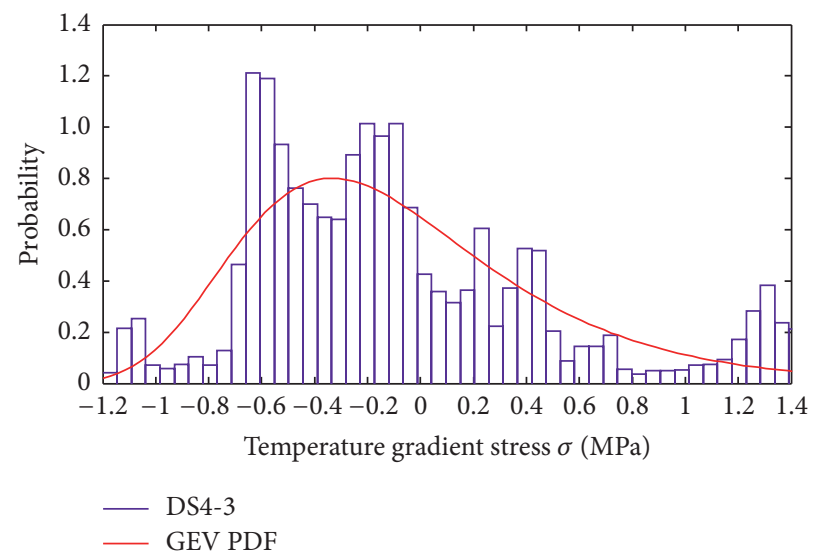

FIGURE 15: Probability density function fitting of the temperature gradient stress of DS4-DS3.

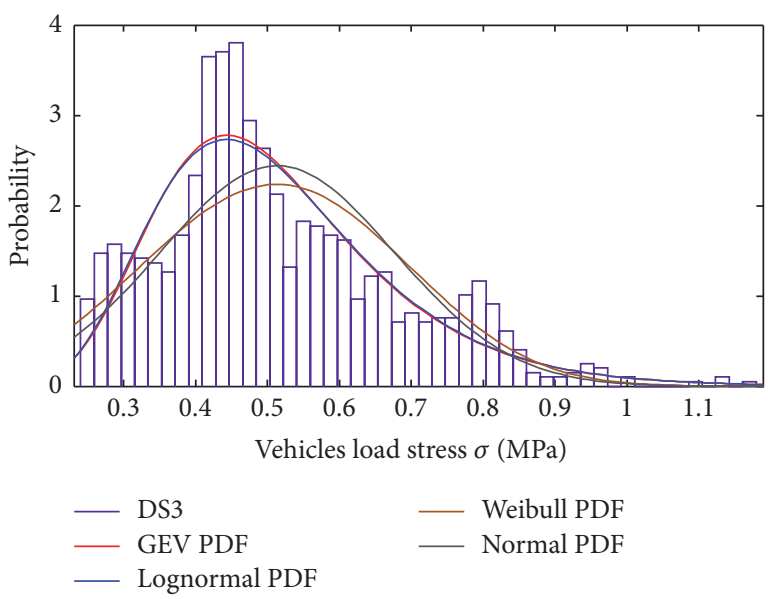

(a) Probability density function fitting of the vehicle load stress of DS3



(b) Probability density function fitting of the vehicle load stress of DS4

FIGURE 16: Histogram of vehicle induced stress and probability density functions.

(DS1 and DS4) present much bigger on June 14, June 17, and June 18 (Figure 17(a)). However, the trend of failure probabilities shows obviously individual difference day by day, which is mainly caused by the temperature gradient stress alternative variation between the top plate and the bottom plate. From Figure 17(b), it is obvious to find out that the failure probability of ES2, located on the top plate, is much bigger than that in other measured positions. For cross section $\mathrm{E}$, it seems that the temperature gradient induced tensile stress plays a leading role on the top plate, which illustrates that the monitored place ES2 is greatly prone to cracking with long-term repeatedly temperature load effect. On support cross sections, due to vehicle load responses being very small, the failure probability calculation results only take account of temperature gradient load (Figure 17(c)), and the failure probabilities of section $\mathrm{C}$ and section $\mathrm{F}$ are lower than $5 \mathrm{e}^{-4}$ during the whole week which indicates that these cross sections are in the safe states. In conclusion, from the results of failure probability during a week, the bridge is in good condition while more attention should be paid to temperature gradient induced tensile stress.

\section{Conclusion}

Strain measurements of a prestressed concrete continuous box-girder bridge were presented based on the long-term field monitoring system. These measurements were recorded just after the bridge was open for traffic. A reliability assessment method for PSC continuous box-girder bridges based on SHM strain measurements was proposed. The probability density function fitting of the load effect dissatisfying the normal distribution was transformed according to equivalent normalization method. The daily failure probabilities of monitored positions were calculated for assessment of this bridge.

The study has led to the following conclusions:

(1) The measured daily strain represents the positive correlation with the ambient temperature of outside box girder. The slopes of the top plate are much bigger than the bottom plate, which means the top plate is more sensitive than the bottom plate to the high temperature whereas the low temperature more easily produced strain on the bottom plate. 


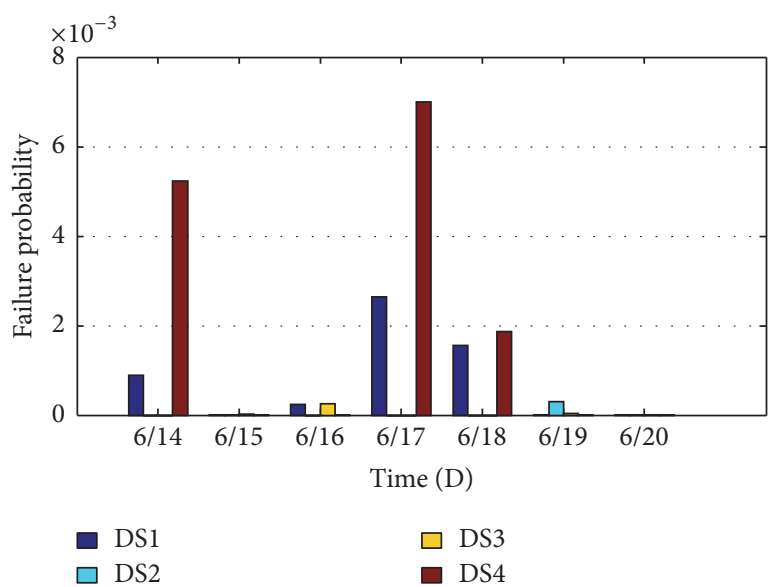

(a) Failure probability of DS1 DS4



(b) Failure probability of ES1 ES4

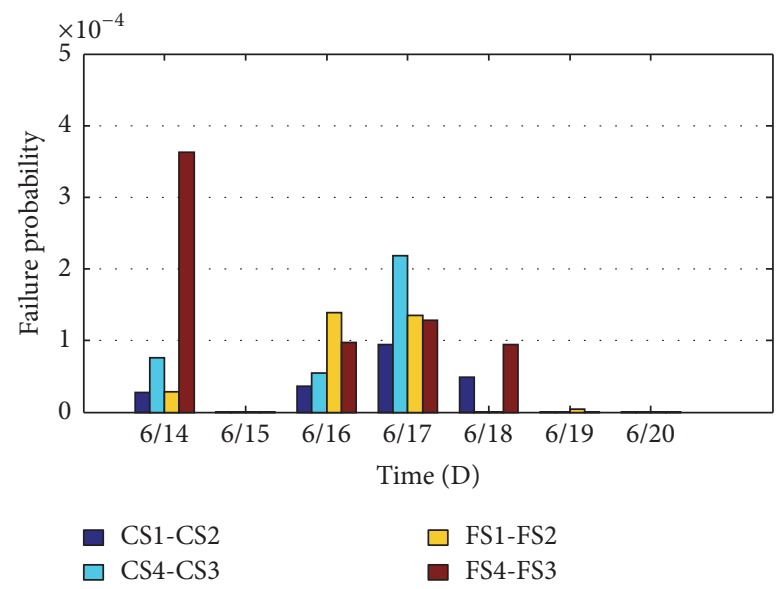

(c) Failure probability of sections $\mathrm{C}$ and $\mathrm{F}$

FIGURE 17: Failure probability.

(2) The seasonal strain variation presents a negative correlation with the uniform temperature.

(3) The solar energy needs a few hours for transferring along the vertical cross sections from the top plate to the bottom plate. The relative tensile strain is alternating between the top plate and the bottom plate during the daily time series. It is a factor causing cracks and damage with this temperature gradient on the cross section.

(4) Generalized extreme value distribution is recommended for temperature gradient stress and vehicle induced stress fitting for this box-girder bridge.

(5) The failure probability calculation results of cross sections can be used to assess the local security state. For this case, the failure probabilities of each section are all very small. One should obtain the verification of a bridge in unsafe condition while the failure probability continues to increase.

(6) The reliability method has great potential in predicting the bridge safety condition with determining partial factors of the limit equation.

\section{Conflicts of Interest}

The authors declare that they have no conflicts of interest.

\section{References}

[1] F. Surre, T. Sun, and K. T. Grattan, "Fiber optic strain monitoring for long-term evaluation of a concrete footbridge under extended test conditionss," IEEE Sensors Journal, vol. 13, no. 3, pp. 1036-1043, 2013.

[2] S. Chakraborty and J. T. DeWolf, "Development and implementation of a continuous strain monitoring system on a multigirder composite steel bridge," Journal of Bridge Engineering, vol. 11, no. 6, pp. 753-762, 2006.

[3] B. J. A. Costa and J. A. Figueiras, "Fiber optic based monitoring system applied to a centenary metallic arch bridge: design and installation," Engineering Structures, vol. 44, pp. 271-280, 2012.

[4] F. Matta, F. Bastianini, N. Galati, P. Casadei, and A. Nanni, "Distributed strain measurement in steel bridge with fiber optic sensors: validation through diagnostic load test," Journal of Performance of Constructed Facilities, vol. 22, no. 4, pp. 264-273, 2008.

[5] B. H. M. P. Wijesinghe, S. A. Zacharie, K. D. Mish, and J. D. Baldwin, "Design and development of in situ fatigue sensors 
for structural health monitoring of highway bridges," Journal of Bridge Engineering, vol. 18, no. 4, pp. 297-307, 2013.

[6] M. R. Delgrego, M. P. Culmo, and J. T. Dewolf, "Performance evaluation through field testing of century-old railroad truss bridge," Journal of Bridge Engineering, vol. 13, no. 2, pp. 132-138, 2008.

[7] D. M. Frangopol, A. Strauss, and S. Kim, "Bridge reliability assessment based on monitoring," Journal of Bridge Engineering, vol. 13, no. 3, pp. 258-270, 2008.

[8] Y. Q. Ni, H. W. Xia, K. Y. Wong, and J. M. Ko, "In-service condition assessment of bridge deck using long-term monitoring data of strain response," Journal of Bridge Engineering, vol. 17, no. 6 , pp. 876-885, 2012.

[9] D. S. Li, Z. Zhou, and J. P. Ou, "Dynamic behavior monitoring and damage evaluation for arch bridge suspender using GFRP optical fiber bragg grating sensors," Optics and Laser Technology, vol. 44, no. 4, pp. 1031-1038, 2012.

[10] B. J. A. Costa and J. A. Figueiras, "Evaluation of a strain monitoring system for existing steel railway bridges," Journal of Constructional Steel Research, vol. 72, pp. 179-191, 2012.

[11] S. R. Debbarma and S. Saha, "Behavior of pre-stressed concrete bridge girders due to time dependent and temperature effects," in Proceedings of the First Middle East conference on monitoring, Assessment and Rehabilitation of Civil Structures, Dubai, UAE, 2011.

[12] L. E. Rodriguez, P. J. Barr, and M. W. Halling, “Temperature effects on a box-girder integral-abutment bridge," Journal of Performance of Constructed Facilities, vol. 28, no. 3, pp. 583-591, 2014.

[13] Y. Q. Ni, X. G. Hua, and J. M. Ko, "Reliability-based assessment of bridges using long-term monitoring data," Advanced Nondestructive Evaluation I, vol. 321-323, pp. 217-222, 2006.

[14] M. Liu, D. M. Frangopol, and S. Kim, "Bridge safety evaluation based on monitored live load effects," Journal of Bridge Engineering, vol. 14, no. 4, pp. 257-269, 2009.

[15] M. Liu, D. M. Frangopol, and S. Kim, "Bridge system performance assessment from structural health monitoring: a case study," Journal of Structural Engineering, vol. 135, no. 6, pp. 733742, 2009.

[16] S. Li, S. Zhu, Y.-L. Xu, Z.-W. Chen, and H. Li, "Long-term condition assessment of suspenders under traffic loads based on structural monitoring system: application to the Tsing Ma bridge," Structural Control and Health Monitoring, vol. 19, no. 1, pp. 82-101, 2012.

[17] H. W. Xia, Y. Q. Ni, K. Y. Wong, and J. M. Ko, "Reliabilitybased condition assessment of in-service bridges using mixture distribution models," Computers \& Structures, vol. 106-107, no. 5, pp. 204-213, 2012.

[18] Y. Liu, N. W. Lu, and Q. Y. Wang, "Reliability assessment of longspan cable-stayed bridges based on hybrid algorithm," Journal of Highway \& Transportation Research \& Development, vol. 31, no. 7, pp. 72-79, 2014.

[19] X. Wang, Y.-Q. Ni, and K.-C. Lin, "Comparison of statistical counting methods in SHM-based reliability assessment of bridges," Journal of Civil Structural Health Monitoring, vol. 5, no. 3, pp. 275-286, 2015.

[20] C. Chen, R. K. Mosbeh, Z. Wang, Q. Gao, and J. Zhong, "Design of a long-term monitoring system for a PSC continuous Boxgirder bridge," Key Engineering Materials, vol. 619, pp. 1-9, 2014.
[21] C. Chen, M. R. Kaloop, Q. Gao, and Z. Wang, "Environmental effects and output-only model identification of continuous bridge response," KSCE Journal of Civil Engineering, vol. 19, no. 7, pp. 2198-2207, 2014.

[22] P. J. Barr, J. F. Stanton, and M. O. Eberhard, "Effects of temperature variations on precast, prestressed concrete bridge girders," Journal of Bridge Engineering, vol. 10, no. 2, pp. 186-194, 2005. 


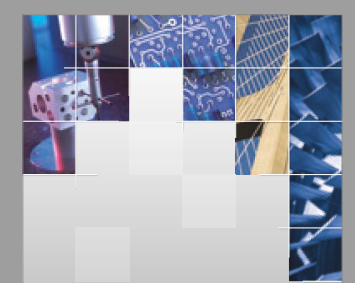

\section{Enfincering}
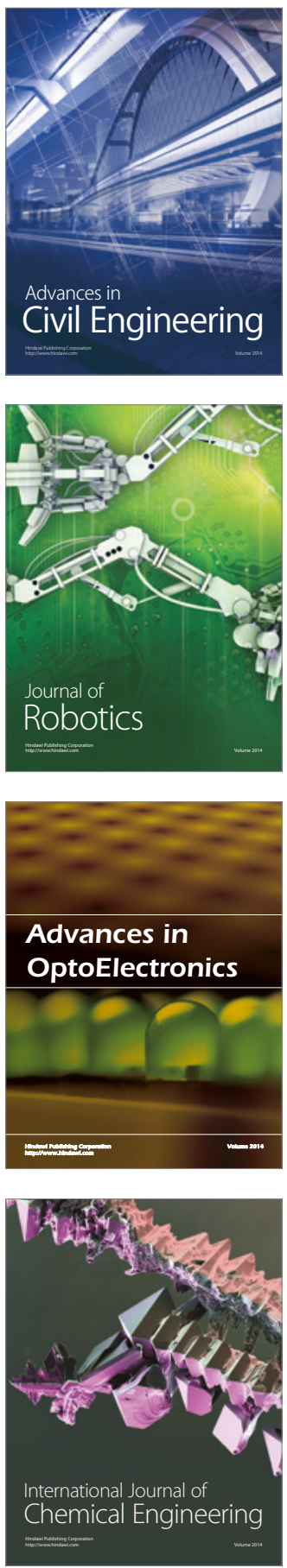

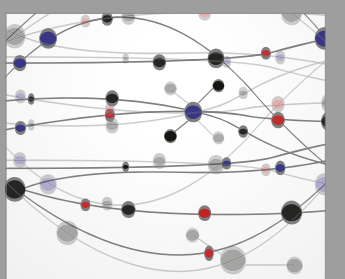

The Scientific World Journal

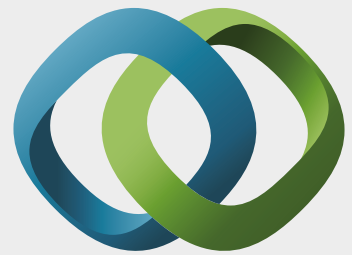

\section{Hindawi}

Submit your manuscripts at

https://www.hindawi.com
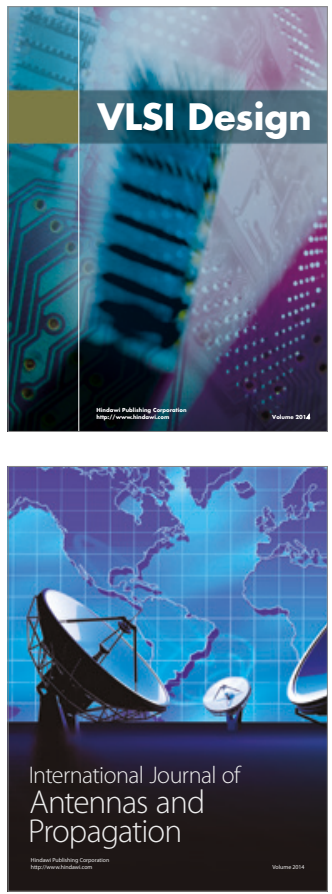

\section{Rotating}

Machinery
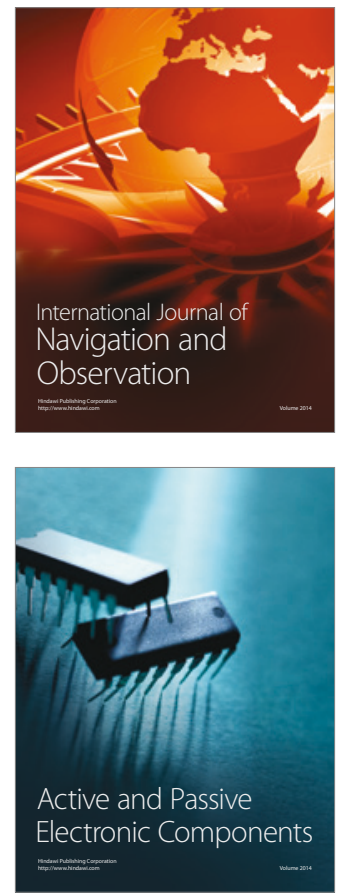

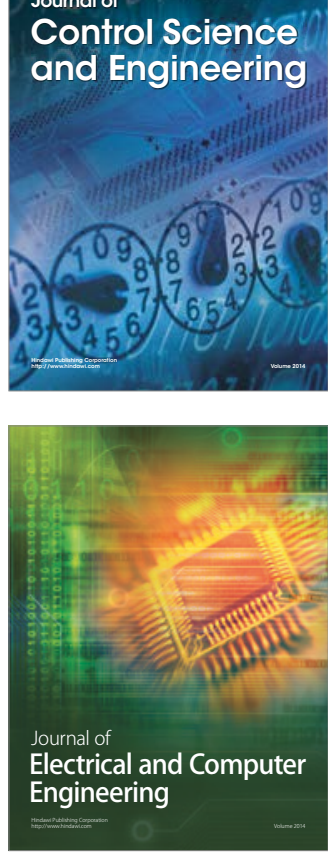

Distributed

Journal of

Control Science

and Engineering
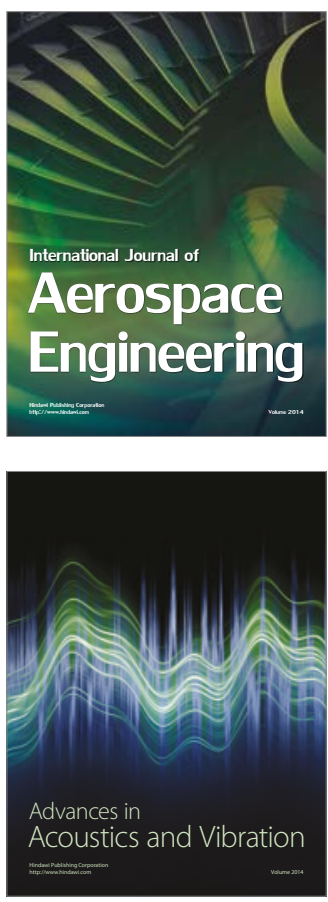

Sensor Networks 